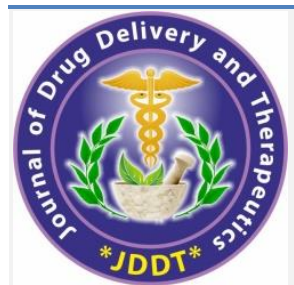

Open Access Full Text Article

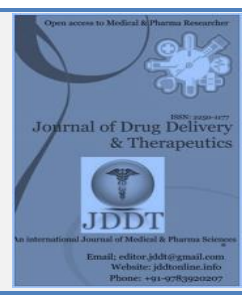

\title{
Antihyperglycemic effect of turmeric aqueous root extract and morphological changes in the pancreas of alloxan-induced hyperglycemic Wistar rats
}

\author{
Samuel I. Ogenyi ${ }^{1 *}$, Ezinne Imoko ${ }^{1}$, Anthony A. Ngokere ${ }^{1}$, Amalachukwu O. Ike ${ }^{2}$ \\ ${ }^{1}$ Department of Medical Laboratory Science, Faculty of Health Sciences and Technology, College of Health Sciences, Nnamdi Azikiwe University, \\ Nnewi Campus
}

${ }^{2}$ Department of Medical Laboratory Science, Faculty of Alide Health Sciences, PAMO University of Medical Sciences, Port Harcourt, Rivers State

\begin{tabular}{ll}
\hline Article Info: & \\
& Article History: \\
&
\end{tabular}

\section{Cite this article as:}

Ogenyi SI, Imoko E, Ngokere AA, Ike AO, Antihyperglycemic effect of turmeric aqueous root extract and morphological changes in the pancreas of alloxan-induced hyperglycemic Wistar rats, Journal of Drug Delivery and Therapeutics. 2021; 11(5-S):19-24

DOI: http://dx.doi.org/10.22270/jddt.v11i5-S.5012

\section{*Address for Correspondence:}

Ogenyi Samuel, Department of Medical Laboratory Science, Faculty of Health Sciences and Technology College of Health Sciences, Nnamdi Azikiwe University, Nnewi Campus

\section{Abstract}

Introduction: The study aims to evaluate the anti-hyperglycaemic effect of turmeric and the histological changes in the pancreas of adult Wistar rats.

Materials and Methods: Forty adult Wistar rats were divided into four groups of [A-D] ten rats per group. Group A was normal control, group B was diabetic control, group C was treated with $300 \mathrm{mg} / \mathrm{kg}$ weight of extract and group D was $500 \mathrm{mg} / \mathrm{kg}$ body weight. All animals had access to food and water ad libitum. Aqueous extract of turmeric was administered orally, once daily for 14 days. The rats were then anaesthetized with dichloromethane before sacrifice and sample collection. Pancreatic tissues were processed, stained using the hematoxylin and eosin (H\&E) method. Blood glucose estimation was determined using the glucose oxidase method.

Results: The mean body weights of the rats across groups were not statistically significant. Similarly, blood glucose levels across groups revealed a progressive statistically significant increase from group A to D and from day one to day 17. Pairwise comparison of group A with B, C and D showed a statistically significant increase but a comparison of Group B with C and D were not significant.

Discussion: There was progressive body weight increase of the rats from day one to the final day across all groups and reduction in the blood glucose levels of the animals treated with $300 \mathrm{mg} / \mathrm{kg}$ and $500 \mathrm{mg} / \mathrm{kg}$ body weights, after seven days of treatment, but these, progressively increased with time even with treatment. The overall pancreas features indicate moderate inflammatory changes.

Keywords: turmeric, anti- hyperglycemia, alloxan, Wistar rats

\section{INTRODUCTION}

Turmeric is a herbaceous perennial plant derived from the rhizome of curcumin longa. The plant measures barely three feet in height and produces a flower and stem that is found underground and therefore is a member of the ginger family, Zingiberaceae $\mathbf{1}$. The leaves are alternate and arranged in two rows, which are divided into leaf sheath, petiole, and leaf blade from the leaf sheaths, a false stem is formed. The petiole is 50 to $115 \mathrm{~cm}$ (20 to 45 inches) long. The simple leaf blade is usually 76 to $115 \mathrm{~cm}$ (30 to 45 inches) long and rarely up to $230 \mathrm{~cm}$ ( 91 inches). They have a width of 38 to $45 \mathrm{~cm}$ (15 to 18inches) and are oblong to an elliptic narrowing at the tip. In SouthSouth East Asia, Turmeric is primarily cultivated in India, Taiwan, Sri Lanka, Burma (Myanmar), Nigeria, Australia, West Indies, Peru, Jamaica, and some other Caribbean and Latin American countries. About $78 \%$ of the world turmeric production, India is the largest consumer and exporter of turmeric 2. Turmeric, which is root-like in nature produces a stem that supplies its yellow vibrant colour known as curcumin. Curcumin is the healing substance in turmeric, which has significance for anti-inflammatory properties. Turmeric, which is affectionally called "kitchen queen", has been used in traditional medicine as a household remedy for various diseases, including biliary disorders, anorexia, cough, diabetic wound, hepatic disorders, rheumatism and sinusitis mention but a few ${ }^{3}$. Turmeric has been shown to have a wide spectrum of biological actions, which includes its anti-inflammatory, anti-oxidant, anti-carcinogenic, antibacterial, anti-coagulant, anti-fungal, anti-fertility, anti-ulcer, hypotension and hypocholesterolemic activities 4. Safety evaluated studies indicate that both turmeric and curcumin are well tolerated at a high dose without any toxic effects. Thus, turmeric and its constituents have the potential for the development of modern medicine for the treatment of various diseases.

Diabetes mellitus may be defined as a metabolic disorder of multiple aetiology characterized by chronic hyperglycemia with disturbance of carbohydrate, fat and protein metabolism, resulting from defects in insulin action, insulin 
secretion or both $\mathbf{5}$. It could present either as Type-1 diabetes characterized by autoimmune destruction of the pancreatic beta-cell resulting in an absolute deficiency in insulin or Type -2 diabetes (T2DM), characterized by insulin resistance and/or reduced production of insulin ${ }^{6}$. Type-2 diabetes is the most common type of the disease worldwide is increased prevalence in the present time 3,7 . The pathogenesis of type- 2 diabetes mellitus (T2DM) is complex 7 and involves the interaction of genetic and environmental factors. The progressive disorders caused by a combination of insulin resistance and $\beta$-cell dysfunction is associated with an increased and premature risk of cardiovascular disease as well as specific microvascular complication such as retinopathy, nephropathy and neuropathy, stroke, ischemic heart disease and diabetic foot $\mathbf{8}$.

Diabetes is one of the most important non-communicable diseases worldwide with rapidly increasing incidence $\mathbf{9 , 1 0 , 1 1}$, 12. In a systematic review, Dahiru and Shehu 10 highlighted the report of the International Federation of Diabetes (IFD) atlas, which reported that about 382 million people $(8.3 \%$ of the adult world population) had Diabetes in 2013, with about $80 \%$ of this number living in middle and low-income countries. The authors also reported that the global disease burden was expected to rise to 592 million people in less than 25 years and further noted that 41.4 million people in Sub-Saharan Africa, representing 109\%, were expected to have diabetes by 2035 . This is aside from about 62\%undiagnosed cases. Nigeria has been reported to have the highest number of people with diabetes with an estimated 3.9 million people (extrapolated prevalence of $4.99 \%$ ) of the adult population aged 20-79-year-old 10. Ogbera and Ekpebegh 13 in a related study put the prevalence of diabetes at $8-10 \%$, with type 2 diabetes mellitus (T2DM) accounting for more cases. Adeloye et al $\mathbf{1 1}$ in a systemic review and meta-analysis reported an age-adjusted prevalence rate of T2DM in Nigeria to be 20-79 years, representing an increase from $2.0 \%$ in 1990 to $5.7 \%$ in 2015 and accounting for over 874000 and 4.7 million cases, respectively. This is not dissimilar to the report of a $5.77 \%$ prevalence rate by Uloko et al $\mathbf{1 2}$ in an earlier study.

The management of diabetes mellitus is usually aimed at glycaemic control using Glucophage based therapy and insulin replacement chemotherapy $\mathbf{9}, \mathbf{1 3}$. According to Ogbera and Ekpebegh 13, oral hypoglycaemic agents are readily accessible and acceptable to persons with Diabetes Mellitus but the cost is borne in most instances, by individuals and often payment is "out of pocket". The authors further opined that diabetes patients spend not less than $29 \%$ of their monthly income in acquiring insulin and therefore, advocate for effective complementary and alternative anti-diabetic control options. In a similar but independent report, Oguejiofor et al ${ }^{9}$ ) noted that the global cost of diabetes care runs in billions with $11 \%$ of global expenditure on healthcare in 2011 being on diabetes care. Sub Saharan Africa and Nigeria, to be specific is faced with a huge burden of diabetes care, due largely to lack of regular access to major anti-diabetic drugs and care, especially insulin at affordable cost. These possess major challenges to patients and lead to underuse of these agents and avoidable metabolic complications. Diabetes does not only impose huge costs but diminishes economic productivity to the patients, their households and society. The need for more affordable and tolerable management options, which will not only reduce the economic burden but also eliminate the side effects of most anti-diabetic drugs, becomes imperative.

Various authors 9, 14, 15 have studied the anti-diabetic and anti-hyperglycemic potentials of turmeric extracts. In an earlier study, Ghorbani et al $\mathbf{1 4}$ observed and reported that turmeric extract is not only useful as food but is beneficial in many respects. The authors reported that turmeric reduced blood glucose level, keeping it within normal ranges and suppress the inflammatory effects caused by hyperglycaemia. This, according to them was because of its ability to reduce hepatic glucose production. In a related study, using an animal model, Padhye et al $\mathbf{1 5}$ reported a significant reduction in blood glucose levels in diabetic induced Wistar rats. Similarly, Tsiani et al $\mathbf{3}$ in a review study reported the antioxidant, anti-inflammatory, hepatoprotective, nephroprotective, neuroprotective, immunomodulatory and antidiabetic properties of turmeric extract.

Tumeric extract was not only reported to reduce blood glucose levels but reduced glycated haemoglobin down to the negative control levels 16,17. The authors opined that the plant should be used as a dietary supplement for the management of diabetes mellitus and protection of the liver and kidney against the complications of the disease. The present study aims to evaluate the anti-hyperglycaemic effect of turmeric root extract and the biochemical changes in the pancreas of alloxan-induced diabetic Wistar rats.

\section{MATERIALS AND METHODS}

\section{Study Area and Study design}

The study was an experimental design using an animal model, carried out at the Animal House of the College of Health Sciences, Nnamdi Azikiwe University, Nnewi Campus. Ethical approval was obtained from the ethics committee of the Faculty of Health Sciences and Technology, Nnamdi Azikiwe University, Nnewi Campus.

\section{Experimental Design}

The current study was carried out using 40 adults (11-12 week old) Wistar rats with body weights ranging from 120$220 \mathrm{~g}$, which were bought from the Veterinary Science Department of Imo State University (IMSU). The rats were divided into four (4) groups (A-D) with 10 rats in each group and were allowed to acclimatize for two weeks before the commencement of experimental procedures. The animals were fed with standard Pfizer-branded rodent feed chow obtained from Livestock Feed, Nigeria Ltd. All animals were allowed access to food and water ad libitum.

Group A: Normal control (10 rats). Animals received food and water only.

Group B: Diabetic control (10 rats). Alloxan-induced diabetic rats, without administration of turmeric extract

Group C: Alloxan-induced diabetic rats (10 rats) treated with a low dose of turmeric $(300 \mathrm{mg} / \mathrm{kg} /$ body weight)

Group D: Alloxan-induced diabetic rats (10 rats) treated with a low dose of turmeric $(500 \mathrm{mg} / \mathrm{kg} /$ body weight).

The body weights of the animals were monitored weekly while the extract at the required doses was administered orally for 14 days.

\section{Collection and extraction of plant material}

The turmeric root plant was procured and identified by a botanist at the Department of Botany, Faculty of Natural Sciences, Imo State University, Owerri, where a sample was deposited in the Herbarium with a voucher no of IMSUH 001. The turmeric plant root was washed, processed into powder extraction carried out by the method described by Joji et al 18. The extract (dry weight value was $19.9 \mathrm{~g}$ ) was kept in a dry clean container and stored in a refrigerator, until ready to use. 


\section{Induction of diabetes with alloxan}

Diabetes was induced in the rats by injecting $140 \mathrm{mg} / \mathrm{kg}$ body weight of alloxan monohydrate, intra-peritoneally after overnight fasting 19. Seventy-two (72) hours after, the rats were confirmed diabetic (that is random glucose concentration greater than $200 \mathrm{mg} / \mathrm{dL}$ ) using the test, "Glucose estimation method".

\section{Collection of Samples}

At the end of the experimental procedure, the animals were anaesthetized with Dichloromethane, blood samples were collected through the cardiac puncture into fluoride bottles using 21 gauge $(21 \mathrm{G})$ needles mounted on a $5 \mathrm{ml}$ syringe. Necropsy was performed and the pancreas was excised and freed from the adventitia, blotted with tissue paper, weighed, sectioned and fixed in 10 $\%$ formal saline for histological evaluation 20. Blood samples were allowed to clot, centrifuged at 3000 r.p.m for ten minutes, the serum for glucose estimation, separated using a Pasteur pipette.

\section{Blood glucose assay}

Serum blood glucose for each sample was determined using the glucose oxidase method as described by Kim et al $\mathbf{2 1}$

\section{Tissue processing, Sectioning and staining}

The fixed pancreas samples were processed, embedded in paraffin wax, $5 \mu$ thick sections cut using a rotary microtome and sections stained by Haematoxylin and Eosin (H\&E) staining method 22.

\section{Microscopy}

The stained slides were examined using x10 and $\mathrm{x} 40$ objectives of a binocular optical microscope. Micrographs of sections were taken and histological architecture of samples compared across study groups.

\section{Statistical analysis}

Mean body weight values, as well as serum glucose levels, were compared across groups using a one-way analysis of variance (ANOVA). Data were analyzed using SPSS software (version 21). Results were presented as Mean \pm S.D. Probability $(\mathrm{P})$ values less than $(\mathrm{P}<0.05)$ were considered significant.

\section{RESULTS}

The results of the present study were presented in tables and figures. The mean body weight of the rats across the four groups and the different treatment periods were not statistically significant (Table 1). Similarly, a comparison of blood glucose levels across study groups revealed a progressive statistically significant increase of blood glucose from group A to D and from day one to day 17. Pairwise comparison of group A versus B, C and D showed a statistically significant increase but a comparison of Group B with $C$ and D were not significant (table 2-4).

Table 1: Comparison of body weights of Wistar rats across groups

\begin{tabular}{|c|c|c|c|c|}
\hline Duration of treatment & Study group & Mean \pm Sd $(\mathrm{kg})$ & f-value & p-Value \\
\hline \multirow[t]{4}{*}{ Initial (day1) } & $\mathrm{A}$ & $173.280 \pm 30.49$ & & \\
\hline & $\mathrm{B}$ & $155.200 \pm 18.29$ & & \\
\hline & $\mathrm{C}$ & $195.190 \pm 22.46$ & 4.273 & 0.011 \\
\hline & $\mathrm{D}$ & $168.380 \pm 28.69$ & & \\
\hline \multirow[t]{4}{*}{ Middle (day10) } & $\mathrm{A}$ & $177.310 \pm 29.93$ & & \\
\hline & $\mathrm{B}$ & $170.780 \pm 15.99$ & & \\
\hline & $\mathrm{C}$ & $195.190 \pm 30.19$ & 1.799 & 0.165 \\
\hline & $\mathrm{D}$ & $172.460 \pm 26.81$ & & \\
\hline \multirow[t]{4}{*}{ Final (day17) } & A & $180.780 \pm 29.73$ & & \\
\hline & $\mathrm{B}$ & $187.010 \pm 15.43$ & & \\
\hline & $\mathrm{C}$ & $195.640 \pm 31.25$ & 1.015 & 0.397 \\
\hline & $\mathrm{D}$ & $176.410 \pm 25.37$ & & \\
\hline
\end{tabular}


Table 2: Comparison of blood glucose levels of Wistar rats across groups

\begin{tabular}{|c|c|c|c|c|}
\hline Duration of treatment & Study group & Mean \pm Sd $(g / d L)$ & f-Value & $\mathrm{p}$-Value \\
\hline \multirow[t]{5}{*}{ Initial (day1) } & A & $112.200 \pm 5.34$ & & \\
\hline & B & $108.000 \pm 10.37$ & & \\
\hline & $\mathrm{C}$ & $95.600 \pm 11.06$ & 6.052 & 0.002 \\
\hline & $\mathrm{D}$ & $100.100 \pm 10.63$ & & \\
\hline & A & $113.700 \pm 4.49$ & & \\
\hline \multirow[t]{4}{*}{ Middle (day 10) } & B & $373.700 \pm 64.08$ & & \\
\hline & $\mathrm{C}$ & $352.400 \pm 110.89$ & 22.474 & 0.001 \\
\hline & $\mathrm{D}$ & $374.300 \pm 110.75$ & & \\
\hline & A & $117.100 \pm 2.13$ & & \\
\hline \multirow[t]{3}{*}{ Final (day 17) } & B & $512.300 \pm 94.71$ & & \\
\hline & $\mathrm{C}$ & $513.500 \pm 105.24$ & 42.991 & 0.001 \\
\hline & $\mathrm{D}$ & $531.400 \pm 132.69$ & & \\
\hline
\end{tabular}

Table 3: Pairwise comparison of blood glucose levels across different levels of treatment

\begin{tabular}{|c|c|c|c|c|}
\hline Duration of treatment & Groups & Mean difference & Standard error & $\mathrm{p}$-Value \\
\hline \multirow[t]{6}{*}{ Initial (day1) } & A vs. B & 4.200 & 4.315 & 1.000 \\
\hline & A vs. C & $16.600^{*}$ & 4.315 & 0.003 \\
\hline & A vs. D & $12.100^{*}$ & 4.315 & 0.048 \\
\hline & B vs. C & $12.40000^{*}$ & 4.315 & 0.041 \\
\hline & B vs. D & 7.90000 & 4.315 & 0.452 \\
\hline & C vs. D & -4.500 & 4.315 & 1.000 \\
\hline \multirow[t]{6}{*}{ Middle (day 10) } & A vs. B & $-260.000^{*}$ & 37.874 & 0.001 \\
\hline & A vs. C & $-238.700^{*}$ & 37.874 & 0.001 \\
\hline & A vs. D & $-260.600^{*}$ & 37.874 & 0.001 \\
\hline & B vs. C & 21.300 & 37.874 & 1.000 \\
\hline & B vs. D & -0.600 & 37.874 & 1.000 \\
\hline & C vs. D & -21.900 & 37.874 & 1.000 \\
\hline \multirow[t]{6}{*}{ Final (day 17) } & A vs. B & $-395.200^{*}$ & 43.391 & 0.001 \\
\hline & A vs. C & $-396.400^{*}$ & 43.391 & 0.001 \\
\hline & A vs. D & $-414.300^{*}$ & 43.391 & 0.001 \\
\hline & B vs. C & -1.200 & 43.391 & 1.000 \\
\hline & B vs. D & -19.100 & 43.391 & 1.000 \\
\hline & C vs. D & -17.900 & 43.391 & 1.000 \\
\hline
\end{tabular}

* Significant level: $\mathrm{p}<0.05$

\section{Histological findings}

The pancreas section of the control showed normal histological architecture (group A). The pancreas section showed destruction of cells of the islet of Langerhans, the beta cells disappeared under necrosis. Beta cells destruction

resulted in hyperglycemia. Overall features are suggestive of inflammatory responses (group B). In groups C and D, pancreas morphology showed moderate leucocytes infiltration of acini. The overall features indicate moderate inflammatory changes. 

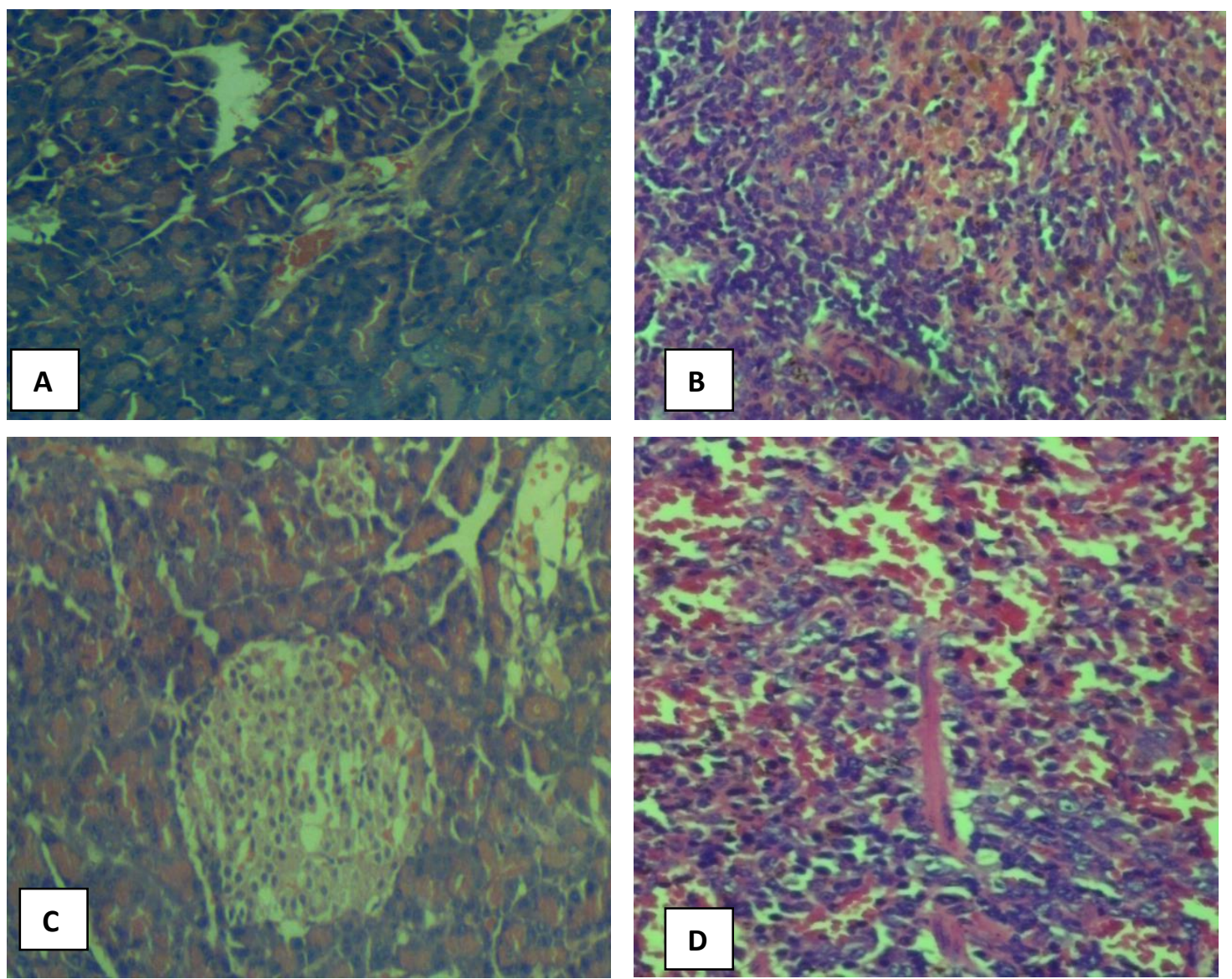

Figure 1: Photomicrograph of the pancreas of Wistar rat shows: (A) architecture consistent with normal pancreas histology; (B) degenerative changes of the beta cells; (C) moderate inflammatory changes and (D) infiltration of inflammatory cells (H\&E ' $X$ 100).

\section{DISCUSSION}

The present study was carried out to evaluate the antihyperglycaemic effect and histomorphological changes of the turmeric root extract in the pancreas of alloxan diabetic induced Wistar rats. Numerous studies had reported the anti-diabetic effect of turmeric extract on animals $3,14,15,16$, 17.

The study observed and reported a progressive bodyweight increase of the rats from day one to the final day of the study across all study groups. This was corroborated by the various authors and especially an earlier study by Murugan and Pari 23. Progressive weight gain in hyperglycaemic rats could be because of the protective effect and nutritive value of turmeric. The initial loss of appetite could have resulted from the oral administration of turmeric extract, which has a bitter taste $\mathbf{2 4 , 2 5}$ or the effect of induction of diabetes. The extract, therefore, served as food and as medicine.

The blood glucose levels of the animals in tests groups were reportedly elevated beyond the reference range $(>200 \mathrm{mg} / \mathrm{dL})$ after treatment with alloxan. There was a reduction in the blood glucose levels of the rats treated with 300 and $500 \mathrm{mg} / \mathrm{kg}$ body weights after 7 days of treatment with turmeric extract, but these progressively increased with time even with treatment. This disagrees with the report of most authors $\mathbf{3}, \mathbf{1 4}, \mathbf{1 5}, \mathbf{1 6}, 17$ who observed a progressive decrease in blood glucose levels when treated with turmeric extract. In the review study, Tsiani et al 3 reported that turmeric extract at a dosage of $100 \mathrm{mg} / \mathrm{kg}$ body weight per day, reduced the blood glucose of Wistar rats within 6 to 12 weeks. This is opposed to the 7 to 14 days administration of the extract in the present study. Recall that the study aims to determine if reduction could be achieved within a reduced period using a higher dose of the extract. One could, therefore, deduce that despite the progressive blood glucose increase during treatment, there is a tendency that it will reduce with prolonged administration. This inference may be backed up by the fact that the diabetic rats showed no sign of diabetes or dietetic complications. There was neither loss of appetite, dehydration nor weight loss evident with diabetics, rather the animals looked healthy and active. This observation was seen in both the low dose $(300 \mathrm{mg} / \mathrm{kg})$ and high dose $(500 \mathrm{mg} / \mathrm{kg})$, implying that increased dosage may not significantly affect glucose control but prolonged administration

The morphological derangement of the pancreas tissue for the test group B as reported in the present study is not unlikely, since the animals were treated with alloxan, which destroys pancreatic beta cells. Similarly, the moderate inflammatory changes observed and reported for the groups treated with turmeric extract could be an indication of the protective effect of turmeric on the pancreas. This corroborates the earlier study by Nwawuba et al $\mathbf{1 6}$ and Abdalla and Mahmoud 17. It is, therefore, could be concluded from the findings of this study, that turmeric extract has an anti-hyperglycaemic effect, though at a prolonged usage. Diabetics may, therefore, include the herb in their daily diet.

\section{CONCLUSION}

Turmeric extract lowers blood glucose and protects the architecture of the pancreas. The lowering effect is achieved 
on prolonged usage. It is therefore, recommended that diabetics include turmeric plant in their daily diet.

\section{Conflict of interest}

The authors declare that there is no conflict of interest

\section{Acknowledgement}

The authors wish to appreciate the entire staff of the department of Medical Laboratory Science, Nnamdi Azikiwe University, Nnewi Campus and Botany department, Imo State University for providing enabling environment for the successful completion of the study.

\section{REFERENCES}

1. Priyadasarini KI. The Chemistry of Curcumin from the extraction to a therapeutic agent. Molecules 2014; 19:20091-112. https://doi.org/10.3390/molecules191220091

2. Deepa KM.The Golden Spice. Market Survey, facts for you. 2007; 51:45-6.

3. Tsiani E, Hartogh DJD, Gabriel A. Antidiabetic Properties of Curcumin II: Evidence from In Vivo Studies. Nutrients 2020; 12:58 https://doi.org/10.3390/nu12010058

4. Araujo A C, Leon L L. Biological Activities of Curcumin Longa L. Memorias Instituto Oswaldo Cruz 2001; 96:723-28. https://doi.org/10.1590/S0074-02762001000500026

5. Anna LS, Marinez DOS, Ana PS, Maria das Gracias, C. Haemostatic Changes in patients with 2 diabetes mellitus. Rev Bras Hematol Hemoter 2010; 32:6.

6. Kumar V, Abbas AK, Fausto N, Mitchell RN, editors. Robbin Basic pathology. Anaemia and chronic inflammation. Saunders Elsevier USA; 2007.

7. Amouoghli T B, Mohajeri D, Safarmashaei S. Protective Effect of Turmeric (Curcuma Longa Linn.) Powder on Early Diabetic Nephropathy in Rats. Advances in Environmental Biology 2011; 5(5):946-51.

8. Leticia AS, Doliveria MS, Paula SA, Das Cratas MC (2010). Hemostatic changes in patients with type 2 diabetes mellitus. Rev Bras Hematol Hemoter 2010; 32(6):482-88.

9. Oguejiofor O, Odenigbo C, Onwukwe C (2014) Diabetes in Nigeria: Impact, Challenges, Future Directions. Endocrinol Metab Synd 2014; 3:130. https://doi.org/10.4172/2161-1017.1000130

10. Dahiru T, Aliyu AA, Shehu AU. A review of population-based studies on diabetes mellitus in Nigeria. Sub-Saharan Afr J Med 2016; 3:59-64. https://doi.org/10.4103/2384-5147.184351

11. Adeloye D, Ige JO, Aderemi AV, Adeleye N, Amoo EO, Auta A, Oni G. Estimating the prevalence, hospitalisation and mortality from type 2 diabetes mellitus in Nigeria: a systematic review and meta-analysis. BMJ Open 2017; 7:e015424. https://doi.org/10.1136/bmjopen-2016-015424

12. Uloko AE, Musa BM, Ramalan MA, Gezawa ID, Puepet FH, Uloko AT et al.. Prevalence and Risk Factors for Diabetes Mellitus in Nigeria: A Systematic Review and Meta-Analysis. Diabetes Ther 2021; 9:1307-16. https://doi.org/10.1007/s13300-018-0441-1
13. Ogbera AO, Ekpebegh C. Diabetes mellitus in Nigeria: The past, present and future. World J Diabetes 2014; 5(6):905-11. https://doi.org/10.4239/wjd.v5.i6.905

14. Ghorbani Z, Hekmatdoost A, Mirmiran P. Anti-Hyperglycemic and Insulin Sensitizer Effects of Turmeric and Its Principle Constituent Curcumin. Int J Endocrinol Metab. 2014 12(4):e18081. https://doi.org/10.5812/ijem.18081

15. Padhye MR, Jogdand SD. Effect of turmeric on alloxan-induced diabetes mellitus in albino rats. Int J Basic Clin Pharmacol 2019; 8(2):264-69. https://doi.org/10.18203/23192003.ijbcp20190145

16. Nwawuba SU, Nwozo SO, Mohammed KA. Dietary Management of Diabetes Mellitus with Focus on Nigeria. Int. J. Diabetes Res 2019; 2(1):26-32.

17. Abdalla E, Mahmoud S. Safely effective hypoglycemic action of stevia and turmeric extracts on diabetic Albino rats. J. Food Biochem. 2021; 45:e13549. https://doi.org/10.1111/jfbc.13549

18. Joji Rl, Beena J, Anjana JC, Ruveena TN. Evaluation of the antibacterial activity of Trichosanthes cucumerina leaf and Cassia didymobotrya Fresen leaves. Int. J. Pharm 2010; 2(4):153-55.

19. Oluwole A, Micheal G, Abdul-Azeez S, Felix 0.Treatment of alloxan-induced diabetic rats with metformin or Glitazones is Associated with Amelioration of Hyperglycaemia and Neuroprotection. The open J diabetic 2012; 5:8-12. https://doi.org/10.2174/1876524601205010008

20. Yemitan OK, Adeyemi 00. Mechanistic assessment of the analgesic, anti-inflammatory and antipyretic actions of Dalbergia saxatilis in animal models: Pharm. Biol 2013; 55(1):898-905 https://doi.org/10.1080/13880209.2017.1283706

21. Kim HY, Park KS, Park HG. Glucose oxidase-like activity of cerium oxide nanoparticles: use for personal glucose meter-based labelfree target DNA detection. Theranostics 2020; 10(10):4507-14. https://doi.org/10.7150/thno.41484

22. Grizzle WE, Stockard CE, Billings PE. The Effects of Tissue Processing Variables Other Than Fixation on Histochemical Staining and Immunohistochemical Detection of Antigens. J Histotechnol 2001; 24(3):213-19. https://doi.org/10.1179/his.2001.24.3.213

23. Murugan P Pari L. Influence of tetrahydrocurcumin on hepatic and renal function markers and protein levels in experimental type 2 diabetic rats. Basic Clin Pharmacol Toxicol 2007; 101(4):241-45. https://doi.org/10.1111/j.17427843.2007.00109.x

24. Iniaghe OM, Malomo SO, Adebayo JO. Proximate composition and phytochemical constituents of leaves of some acalypha species. Pak J Nutri 2009; 8:256 - 58. https://doi.org/10.3923/pjn.2009.256.258

25. Prasad NR, Viswanathan S, Devi JR, Nayak V, Swetha VC, Archana $\mathrm{BR}$, et al. Preliminary phytochemical screening and antimicrobial activity of Samanea saman. J Med Plants Res 2008; 2(10):268 70 . 